\title{
0 solo como estratégia de integração e mudança social na educação formal (durante a pandemia)
}

The SOIL AS A STRATEGY FOR SOCIAL INTEGRATION AND CHANGE IN FORMAL EDUCATION (DURING THE PANDEMIC)

\author{
HeRmon R. Silva ${ }^{1}$, Rosely A. L. ImbernoN ${ }^{1,2}$ \\ 1 - Programa de Pós-Graduação em Ensino e História de Ciências da Terra, Instituto de Geociências, Universidade Estadual de Campinas (Unicamp) \\ 2 - Escola de Artes, Ciências e Humanidades (EACH), Universidade de São Paulo (USP). \\ E-mail: h264268@dac.unicamp.br, imbernon@usp.br.
}

\begin{abstract}
The study of the soil in formal education, by the planting of vegetables at school and in the community, generally involves the implementation of a school vegetable garden. Based on remote learning, adopted as a teaching strategy since the beginning of the social isolation caused by the Covid-19 pandemic, in replacement of face-to-face activities at school, the "school garden" has been developed in E. E. Prof. Francisco de Paula Conceição Jr., located in the south of the city of São Paulo, with students from the $8^{\text {th }}$ year of elementary school in interdisciplinary and transversal activities with 20 students. The action research and the conversation wheel, adopted as a methodological framework, started from everyday problems, observed during social isolation, which were resumed in the face-to-face phase at school. The proposal uses the soil/garden as learning spaces, as an emerging challenge to the pandemic with remote learning, and as an element of integration in the return to face-to-face classes.
\end{abstract}

Resumo: 0 estudo do solo na educação formal, por meio do plantio de hortaliças na escola e na comunidade, envolve, em geral, a implantação da horta escolar. A partir da aprendizagem remota, adotada como estratégia de ensino desde o início do isolamento social provocado pela pandemia de Covid-19, em substituição às atividades presenciais na escola, a "horta escolar" vem sendo desenvolvida na $E$. E. Prof. Francisco de Paula Conceição Jr., localizada na zona sul da cidade de São Paulo, com alunos do $8^{0}$ ano do ensino fundamental, em atividades interdisciplinares e transversais com 20 alunos. A pesquisa-ação e a roda de conversa, adotadas como referencial metodológico, partiram de problemas cotidianos, observados durante 0 isolamento social, que foram retomados na fase presencial na escola. A proposta utiliza 0 solo/horta como espaços de aprendizagem, como um desafio emergente à pandemia com 0 ensino remoto, e como elemento de integração no retorno às aulas presenciais.
Citation/Citação: Silva, H. R., \& Imbernon, R. A. L. (2021). 0 solo como estratégia de integração e mudança social na educação formal (durante a pandemia). Terræ Didatica, 17(Publ. Contínua), 1-12, e021042. doi: 10.20396/td.v17i00.8667180.

Keywords: Hybrid Teaching, Environmental Education, Agroecology. Palavras-chave: Ensino Híbrido, Educação Ambiental, Agroecologia.

Manuscript/Manuscrito:

Received/Recebido: 30/09/2021

Revised/Corrigido: 26/10/2021

Accepted/Aceito: 10/11/2021

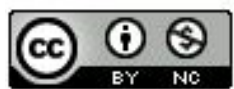

\section{Introdução}

O aumento populacional nos grandes centros urbanos, em todo o planeta, impondo o uso desigual dos recursos naturais pelas sociedades, tem como vítimas os diferentes compartimentos e ecossistemas terrestres, com reflexos impactantes na hidrosfera, na atmosfera e na geosfera.

$\mathrm{Na}$ ótica de um planeta igualitário, visando à erradicação da fome e à promoção de políticas públicas sustentáveis, no ano de 2015 a Organização das Nações Unidas (ONU), com 193 estados membros, divulgou em Nova York o documento: Transformando o Nosso Mundo: A Agenda 2030 para o Desenvolvimento Sustentável. O documento, conhecido como Agenda 2030 (ONU, 2015), constitui um compromisso de governança global: os países se comprometem a cumprir 17 Objetivos de Desenvolvimento Sustentável (ODS) até 2030.
No mesmo ano, a Organização das Nações Unidas para a Alimentação e Agricultura da ONU (Food and Agriculture Organization, FAO) definiu o Ano Internacional do Solo, e proclamou que cerca de um terço dos solos em todo o planeta estão esgotados devido ao uso e ocupação irracionais. A partir dessa constatação, e outros fatores agravantes, a FAO declarou o uso finito do solo, o que implica que como recurso natural o solo não é recuperável quanto à degradação, considerando-se o tempo de vida do homem (FAO 2015).

O solo, como recurso natural, tem extrema importância para a vida humana e demais seres vivos. Para os ecossistemas terrestres é fonte de diversos produtos e insumos, desde a alimentação da vida terrestre, o que inclui a vida humana, até a produção de medicamentos, configurando-se como um divisor notável entre camadas sociais. Tal afir- 
mação impõe uma atenção intrínseca relacionada à exploração, degradação, uso e poluição do solo, necessitando atuação e responsabilidade de todos.

Já passou da hora de a degradação dos solos entrar no radar das políticas públicas. No Brasil, não se sabe exatamente quais seriam as responsabilidades dos diferentes entes governamentais na execução de uma política coerente para conservação dos solos. Hoje parte das ações se localiza no Ministério do Meio Ambiente, outra no Ministério da Agricultura, outra no Ministério do Desenvolvimento Agrário etc. As coisas estão desarticuladas" (Zanella, 2015, p. 5).

As políticas públicas ambientais no Brasil não definem de forma clara a responsabilidade governamental na proteção e conservação do solo e instrumentos de preservação desse recurso natural, uma vez que somente a partir de 2017 o Cadastro Ambiental Rural (CAR), um instrumento fundamental para auxiliar no processo de regularização ambiental de propriedades e posses rurais, passou a ser exigido para o acesso ao crédito rural.

É importante o desenvolvimento de uma política pública estruturante que considere a necessidade de implementação da avaliação de sustentabilidade nos sistemas produtivos, tendo em vista o potencial para minimizar os impactos do uso inadequado dos solos, os quais provocam a perda de, mais ou menos, 7 milhões de hectares por ano. O governo tem papel central para o desenvolvimento da ferramenta, principalmente no âmbito de decisões estratégicas e questões regionais, e as empresas têm um papel especial no âmbito da cadeia do produto e como ator articulador. (Santamaria Filho et al., 2015 p. 30).

Para além das questões políticas de proteção ambiental do solo, devemos apontar que a temática "solo" na Base Nacional Comum Curricular (BNCC) não se apresenta como objeto de conhecimento especificamente, mas é citada de forma transversal dentre as habilidades a serem desenvolvidas pelos alunos, o que não permite ao aluno, futuro cidadão, (re)conhecer o solo como parte dinâmica do meio ambiente.

A atual ignorância sobre o solo parece ser reforçada pelas normas da sociedade. Se permitido, a consideração humana de propriedades distintas associadas à formação do solo deveria começar muito cedo. Infelizmente, a autoeducação sobre o solo geralmente termina na infância. Provavelmente, poderíamos evitar muitos dos problemas que temos com a degradação dos recursos do solo se um interesse precoce pelo solo se desenvolvesse e continuasse ao longo da vida de um ser humano... a educação sobre o solo é conduzida em diferentes partes do mundo, é necessária maior conscientização pública sobre o papel crítico do solo em nossas vidas e como podemos melhorar a educação sobre o solo. (Harrison et al., 2010, p. 1)

\section{A Base Nacional Comum Curricular (BNCC) e as habilidades associadas ao objeto de aprendizagem "solo"}

No ensino formal, assumir o papel de um educador na formação dos alunos em temas transversais, como meio ambiente, é crucial no protagonismo do professor, como sugere Giroux (1997, p. 161): "os professores devem assumir responsabilidades ativas com levantamento de questões sérias acerca do que ensinam". Assim, ao introduzir como objeto de aprendizagem a temática "solo", as perspectivas de aprendizagem envolvem, para além de conhecer a natureza do solo (processos de formação, características físico-químicas, mineralógicas, microbiológicas etc.) compreender como o uso e ocupação do solo devem ser conduzidos de forma a também focalizar a preservação, bem como um uso e ocupação racionais.

Solo é produto de transformação das substâncias orgânicas e minerais da superfície da terra sob a influência dos fatores ambientais que operem por um período muito longo e apresentando uma organização e morfologia definidas. É o meio de crescimento para as plantas, superiores e base da vida para os animais e seres humanos (Schroeder, 2017, p. 14).

De acordo com Vicente et al. (2020), "dentre os diferentes conteúdos relacionados à área de Ciências da Natureza, a abordagem de solos nos livros didáticos se restringe basicamente a dois momentos do Ensino Fundamental: $3^{\circ}$ e $6^{\circ}$ anos". Assim, quando observamos a contextualização do "solo" como objeto de aprendizagem nas Ciências da Natureza na Base Nacional Comum Curricular (BNCC), devemos discutir, também, a importância ambiental desse recurso que é de suma importância para a evolução e manutenção da vida na Terra. 
(...) a área de Ciências da Natureza, por meio de um olhar articulado de diversos campos do saber, precisa assegurar aos alunos do Ensino Fundamental o acesso à diversidade de conhecimentos científicos produzidos ao longo da história, bem como a aproximação gradativa aos principais processos, práticas e procedimentos da investigação científica. Espera-se, desse modo, possibilitar que esses alunos tenham um novo olhar sobre o mundo que os cerca, como também façam escolhas e intervenções conscientes e pautadas nos princípios da sustentabilidade e do bem comum (Brasil, 2018).

$\mathrm{Na}$ Educação Básica as aprendizagens essenciais definidas na BNCC devem concorrer para "assegurar aos estudantes o desenvolvimento de dez competências gerais, que consubstanciam, no âmbito pedagógico, os direitos de aprendizagem e desenvolvimento" (Brasil, 2018).

(...) competência é definida como a mobilização de conhecimentos (conceitos e procedimentos), habilidades (práticas, cognitivas e socioemocionais), atitudes e valores para resolver demandas complexas da vida cotidiana, do pleno exercício da cidadania e do mundo do trabalho. Ao definir essas competências, a BNCC reconhece que a "educação deve afirmar valores e estimular ações que contribuam para a transformação da sociedade, tornando-a mais humana, socialmente justa e, também, voltada para a preservação da natureza" (Brasil, 2013), mostrando-se também alinhada à Agenda 2030 da Organização das Nações Unidas (ONU) (Brasil, 2018, p. 14).

Ao analisarmos as habilidades sugeridas para Ciências nas séries finais no Ensino Fundamental (EF), observamos que as habilidades propostas para diversos objetos de conhecimento em diferentes unidades temáticas poderiam envolver temáticas relacionadas ao uso e ocupação do solo.

$\mathrm{Na}$ Tabela Suplementar 1, apresentamos as Unidades Temáticas para o ensino de Ciências no ensino fundamental séries finais $\left(\right.$ do $6^{\circ}$ ao $9^{\circ}$ ano): selecionamos os objetos de aprendizagem nos quais identificamos situações didáticas em que, apesar de não serem citadas como habilidades relacionadas ao tema "solo", são propostas algumas habilidades em que situações didáticas complementares poderiam ser sugeridas dentre as habilidades pretendidas.

O solo, ao ser abordado pelo professor como objeto de conhecimento, deveria envolver mais do que simplesmente as habilidades propostas na
BNCC para o processo ensino-aprendizagem. Apontamos para um fator importante pouco considerado nas Habilidades indicadas pela BNCC para o ensino de Ciências no ensino fundamental séries finais $\left(6^{\circ}\right.$ aos $9^{\circ}$ anos), pois a compreensão do solo envolve compreender a integração entre os ciclos que compõem o sistema Terra, para além da interação com a biosfera, fatores culturais etc.

O tratamento superficial, principalmente pelo desconhecimento do professor sobre o assunto e a falta de ambientes propícios às aulas práticas, não permite ao aluno (re)conhecer o solo como um recurso natural esgotável, em face aos impactos antrópicos gerados pelo uso e ocupação indevidos, e de acordo com Santos et al. (2018 p. 278) a horta é um laboratório vivo disponível a diferentes atividades didáticas.

A FAO (2020) destaca iniciativas com o pioneirismo de técnicas de agroecologia sendo desenvolvidas em instituições, dentre elas, a escola.

Numerous national institutions, research centers, networks, universities, and schools are including soil biodiversity in their programs. Some of them are also leading research on technological innovations as well as on traditional and agroecological approaches related to soil biodiversity (for example, research, practical application, assessment, indicators, and monitoring) (FAO, 2020, p. 317).

\section{Materiais e Métodos}

O público-alvo da pesquisa foram alunos do $8^{\circ}$ ano do Ensino Fundamental (EF), como atividade de contraturno, de escola da zona sul da cidade de São Paulo, envolvendo para além das componentes curriculares de Ciências da Natureza e Geografia, outras componentes curriculares para alunos do $6^{\circ}$ ao $9^{\circ}$ anos do Ensino Fundamental (EF).

Temas como solo, quando tratados de forma interdisciplinar, contribuem para a compreensão de problemas como a poluição e degradação antrópica, assim como aponta Araújo (2014 p.450) que "o estudo da natureza e da vida pode avançar em direção a propostas interdisciplinar, multidisciplinar e transdisciplinar".

Para a coleta de dados da pesquisa assumimos um conjunto de 20 alunos, que participaram de forma espontânea, devidamente autorizados pelos pais e ou responsáveis (autorizações aprovadas pelo Comitê de Ética em Pesquisa foram enviadas aos 
pais para assinarem e devolverem à escola antes do início do projeto). Pretendeu-se, com esse recorte, dar condições para que os alunos demonstrassem motivação na participação e atuação do conhecimento proposto pelo projeto, pois, de acordo com Lins et al. (2013) o sucesso de novas práticas educativas depende exclusivamente da participação efetiva do educando:

Para a efetividade da aprendizagem, é fundamental destacar o papel do aluno em seu próprio aprender, porque, ao se sentir autor e ator de sua história, ele melhora seu rendimento - algo que é impossível de ser substituído pelas estratégias de ensino, por melhores que sejam (Lins et al., 2013 p. 67).

Ao refletirmos sobre os princípios éticos, a ausência de possíveis alterações na coleta de dados e compromisso dos alunos, professores e comunidade escolar, entendemos que a pesquisa se enquadra em um trabalho participativo, por meio da pesquisa-ação. Ou seja, etapas, decisões e conclusões foram tomadas de acordo com a ciência e participação do público participante.

A pesquisa-ação é inovadora do ponto de vista científico somente quando é inovadora do ponto de vista sociopolítico, isto quer dizer, quando tenta colocar o controle do saber nas mãos dos grupos e das coletividades que expressam uma aprendizagem coletiva tanto na sua tomada de consciência como no seu comprometimento com a ação coletiva (Zuñiga, 1981 apud Thiollent, 2005 p.54).

Com base nos princípios fundamentais da pesquisa-ação, o comprometimento coletivo foi uma das metas fundamentais deste projeto, e a partir das intervenções programadas e realizadas como aulas teóricas e práticas, promoveu-se um cenário de possíveis, e prováveis, mudanças no ambiente escolar.

As Intervenções foram assistidas, sugeridas e, quando necessárias, modificadas pelos professores parceiros (outras componentes curriculares) e gestão escolar, voluntários nesta pesquisa.

De acordo com a nossa compreensão no assunto, o principal ator é quem faz ou está efetivamente interessado na ação. O pesquisador desempenha um papel auxiliar, ou "assessoramento", embora haja situações nas quais os pesquisadores precisam assumir maior envolvimento e responsabilidade, em particular nas situações cercadas de obstáculos políticos ou outros (Thiollent, 2011, p.80).
As intervenções na forma de aulas práticas e teóricas pretendeu realizar um ensino participativo, inclusivo, individual e coletivo, pois como sugere Roldão (2010 p. 18):

[...] ensinar entende-se aqui como desenvolver uma ação especializada, fundada em conhecimento próprio, que consiste em fazer com que alguém aprenda alguma coisa, que se pretende e se considera necessário.

A pesquisa-ação, como método de condução adotado propiciou uma pesquisa dialógica, em que a interdisciplinaridade caracterizou as intervenções, tendo o solo como tema gerador transversal em todas as disciplinas envolvidas.

A pesquisa qualitativa sugerida encontrou desafios metodológicos de como superar o distanciamento entre professor e alunos promovido pelo ensino remoto durante a pandemia de Covid-19, e construir um diálogo em que ao aluno fosse permitido expor e falar sobre suas observações, dúvidas etc. Adotou-se, desta forma, a roda de conversa, adaptada ao ambiente digital, por meio da plataforma de aulas Meet Google, também utilizada para as intervenções no formato de aulas teóricas e práticas.

A aplicação da roda de conversa se baseia em Barbosa \& Horn (2008) que indicam que a ferramenta didática possibilita

(...) esse campo dialógico e democrático, no qual a criança ganha vez e voz, mas que não fala sozinha, já que o adulto, parceiro e sensível às suas necessidades, estão com ela em diferentes momentos. Reconhece-se a criança como sujeito de direitos e ativos na construção de conhecimentos (...). (Barbosa \& Horn, 2008, p. 33).

A roda de conversa possibilita

(...) a construção ou ressignificação do conhecimento, que objetiva esclarecer teoricamente o movimento feito por nós, para tentar evidenciar cientificamente este processo de construção do conhecimento pela mediação dialógica entre educador e educando (Guarda et al., 2017).

Embora a aplicação das rodas de conversa fosse uma metodologia para a qual não encontramos referências de aplicação em ensino a distância, identificamos que tal procedimento permitiria o protagonismo dos alunos em ambiente fora da sala de aula, ressaltando fatores alheios à aula (pelo fato dos alunos assistirem às aulas remotas em suas casas ou outros ambientes que não a escola). 
Desta forma, o protagonismo dos alunos participantes no projeto ocorreu a partir de suas falas, registradas pelo professor, considerando as demandas das intervenções definidas para cada aula. As rodas de conversa propiciaram desenvolver a construção da autonomia, do discurso, do pensamento crítico-reflexivo, das expressões linguísticas e o envolvimento da família durante o período de realização do projeto. Tal fato, ressaltamos, permitiu um diálogo amplificado, o que, muito provavelmente, não seria atingido se tais intervenções fossem realizadas em sala de aula, no ensino presencial. Como destaca Freire (1983):

Não é dizer-se descomprometidamente dialógico; é vivenciar o diálogo. Ser dialógico é não invadir, é não manipular, é não organizar. Ser dialógico é empenhar-se na transformação constante da realidade. Esta é a razão pela qual, sendo o diálogo o conteúdo da forma de ser própria à existência humana, está excluído de toda relação na qual alguns homens sejam transformados em "seres para outro" por homens que são falsos "seres para si". (Freire, 1983 p. 43).

O uso de aplicativos de conversa em grupo, o WhatsApp, foi utilizado pelo professor como forma de organizar as reuniões, receber questionamento e retornar respostas, e manter registro das etapas das aulas práticas, por meio de fotos e vídeos realizados pelos alunos.

Para o retorno às aulas presenciais, com a construção da horta na escola, a proposta do ensino híbrido propiciou potencializar o aprendizado dos alunos. Pois, um fato contundente que a pandemia desencadeou foi a necessidade de assumirmos não estarmos preparados para tais alterações no processo ensino-aprendizagem, e, apesar das mudanças emergenciais, não conseguimos atingir um nível satisfatório da educação de nossos alunos da educação básica. Das desigualdades sociais e econômicas, que cercearam milhares de alunos quanto ao acesso à internet, ao protagonismo dos professores, que não tiveram formação adequada para o ensino remoto; e dos gestores escolares, que jamais enfrentaram situação em contexto similar, o desafio é que ainda deveriam se preparar para o retorno gradual, com ampliação das vacinações, para uma nova fase presencial. Assim, resta um questionamento que se fundamenta em como implementar o ensino híbrido durante a retomada gradual das atividades presenciais?

Assim, a modalidade de ensino híbrido, no presencial e remoto, ocorreu neste projeto de forma síncrona e assíncrona, sobretudo com a presença de tecnologias digitais para a promoção do ensino coletivo e personalizado. O processo remoto incluiu a participação da família e amigos se envolvendo no plantio e cuidados com as hortaliças. Nesse processo Bacich (2015) sugere que

(...) a aprendizagem se constrói em um processo equilibrado entre a elaboração coletivas - por meio de múltiplas formas de colaboração em diversos grupos - e a personalizada - em que cada um percorre roteiros diferenciadores", ação que se inicia a partir do diálogo. (Bacich, 2015 p. 33)

O projeto, originalmente previsto para atividades exclusivamente presenciais, precisou ser adaptado para a modalidade de ensino a distância, fato que motivou os professores a desenvolver estratégias para que as atividades previstas se efetivassem como previsto; contudo, tais estratégias nem sempre conseguiram superar barreiras sociais, econômicas e culturais, impostas pela falta de equipamentos e rede internet na residência de cada aluno (Robinson-Neal, 2021).

Neste aspecto, a pandemia, COVID-19, criou estressores nos recursos das instituições de ensino à medida que a necessidade de mudar para formas mais exclusivas de ensino à distância se apresentaram. À medida que estados, províncias e países fechavam e os líderes governamentais promulgavam leis para restringir o movimento e a concentração, os líderes da educação pressionavam por formas online de ensino e aprendizagem. (Robinson-Neal, 2021 p. 2)

\section{Resultados e Discussão}

No campo da educação, o uso dos Objetivos de Desenvolvimento Sustentável (ODS, Agenda $2030,2015)$ potencializa as aprendizagens formais e informais, em diferentes ambientes, como a sala de aula, o lar do estudante, o ambiente escolar etc. Sob tal perspectiva, identificamos em Freire (1996) elementos que contribuem para a formação cidadã do educando e promoção da autonomia discente, de forma amplificada em direção à comunidade.

Rachel Carson, em seu livro "Primavera Silenciosa” (Silent Spring, 1964) já alertava para a ausência de resiliência e racionalidade quanto à preservação da vegetação, sobretudo nativa, no solo, e seu papel simbiótico. 
[...] O solo e o manto verde da Terra formado pelas plantas constituem o mundo que sustenta a vida em nosso planeta. Embora o homem moderno dificilmente se lembre desse fato, ele não poderia existir sem as plantas que captam a energia do sol e fabricam os alimentos básicos de que ele depende para viver (Carson, 1964, p. 65).

Com o objetivo de relacionar o objeto de aprendizagem e as habilidades sugeridas pelos referenciais didático-pedagógicos utilizados para as sequências didáticas (BNCC), foram construídos indicadores, que direcionaram o diálogo nas rodas de conversas, considerando o aprendizado dos alunos:

1. Os usos múltiplos do solo e seus valores;

2. A importância do solo para a humanidade;

3. O solo como recurso natural;

4. A vegetação e sua importância para a preservação do solo;

5. A relação do solo e o meio ambiente;

6. A natureza do solo e os diferentes tipos de solo;

7. Os seres vivos do solo e sua importância para o plantio;

8. Os diferentes tipos de solo, fertilidade, importância da adubação, o uso de agrotóxicos na agricultura e suas consequências.

As rodas de conversa ocorreram de forma remota no aplicativo Google Meets em pequenos grupos, no máximo oito alunos, e divididos em três sessões. O professor conduziu a roda de conversa mediando, sem intervenção direta, com o uso dos indicadores elaborados.

Durante o diálogo, os alunos foram questionados sobre cada indicador, sem interrupção do pesquisador, e foram motivados a argumentar de forma livre sobre o que sabiam sobre a temática sugerida. Antes da roda de conversa é assegurado ao aluno que sua participação não será avaliada, de forma que a livre manifestação não seja comprometida. De acordo com Yin, (2016 p. 22) o professor/ pesquisador deve [...] ser capaz de escutar de maneira multidimensional [...], ou seja, tornar o momento um diálogo direcionado, mas também, livre de cobranças pedagógicas.

Nos indicadores 1 e 2, referentes aos usos múltiplos do solo, valores e importância para a vida, obtivemos respostas genéricas como: Não tem valor, pois pode pegar em qualquer lugar comparando o solo com a terra (no sentido de chão em que pisamos) e não a sua totalidade; só tem valor quando é para as plantações, esse discurso ratifica a observação anterior, ou seja, os alunos e alunas associam o recurso solo apenas como o horizonte "O", aquele associado à produção agrícola; é importante para as plantas e alimentos, os alunos se debruçaram nesta argumentação genérica, o que novamente confirma a importância do solo somente para o plantio.

Com relação aos alunos que não responderam, em relação aos usos múltiplos do solo no que se refere aos fatores ecológico, econômico, medicinal, cultural, entre outros, o conhecimento deste recurso envolve (re)conhecer o solo e o perfil de evolução, que formam os diferentes horizontes cada qual com características e propriedades importantes no que se refere a manutenção ecológica de um ecossistema, habilidade que possibilita ao estudante conhecer o recurso solo, para além do conceito de "terra para plantar".

Assim, quando perguntado sobre o solo é um recurso natural, seu uso é finito ou infinito; a vegetação e sua importância para a preservação do solo, referentes aos indicadores 3 e 4 , verificamos que muitos alunos não responderam e/ou não sabiam responder, reafirmando o desconhecimento do aluno sobre o solo como recurso natural, sobretudo como recurso finito. Somente um aluno apresentou argumentação sobre a temática, com o comentário é um recurso natural, mas não sei se é finito, o que se espera para um estudante do $8^{\circ}$ ano. Os poucos alunos que responderam associaram a produção de alimentos e proteção do solo, uma indicação de percepção do papel da vegetação na proteção contra os processos erosivos, e preservação do solo, e algumas respostas positivas envolveram a função agrícola do solo importante para alimentos e para o meio ambiente, e somente um aluno apontou que ela (a vegetação) protege o solo, conhecimento esperado.

Segundo o Relatório State of knowledge of soil biodiversity (FAO, 2020), a partir de locais como a escola, torna-se possível a promoção do ensino formal, ou informal sobre o uso racional do solo, e verificamos que muitas habilidades não foram desenvolvidas nas seriações anteriores sobre o uso racional do solo.

Para a sondagem dos indicadores 5 e 6 , a relação do solo com o meio ambiente e a Natureza do solo e os diferentes tipos de solo, esperava-se que o educando discutisse soluções sobre lixo, problemas ambientais em torno da escola e residências, coleta de esgotos, poluentes como o plástico, entre outros; além do conhecimento sobre o solo, relacionando-o com ecossistemas e biomas. 
Quando perguntado sobre qual a relação do solo e meio ambiente, obtivemos respostas como solo e meio ambiente é a mesma coisa, e os discursos que se enquadram nesta resposta apontam para uma generalização de que o solo e o meio ambiente são a mesma coisa; tem relação com as plantas e limpa o meio ambiente, discurso que se enquadra nesta resposta, e provavelmente aponta para solo e meio ambiente como sinônimos.

Ao discutir a relação do solo e o meio ambiente (indicador 5) o grupo demonstrou que compreende essa relação, denotando a importância do solo. De forma contrária, ao discutirmos o indicador 6 (natureza do solo e os diferentes tipos de solo) o grupo demonstrou desconhecer processos de formação do solo, a partir das rochas, o que caracterizaria diferentes tipos de solos. As citações são quase todas diferentes, tais como imagino que tem terra preta, seca, úmida; ou em o que dá para plantar e o que não dá, demonstram total ausência de conhecimentos, mas a percepção visual, associada à cor, umidade, e relação com plantio é evidente.

A concepção identificada de solo se aproxima novamente de terra, chão em que pisamos, e não como um recurso natural, e, novamente, o conceito solo como recurso natural é compreendido somente para um único horizonte, considerando o perfil de evolução pedogenético, àquele relacionado à agricultura (horizonte $\mathrm{O}$ ).

A educação ambiental no ensino deve refletir também sobre ambientes urbanos com altas taxas de lixos, enchentes e poluição do solo, devido ao descarte de resíduos de forma aleatória, e esses aspectos mostram que a observação cotidiana do aluno se sobrepõe ao conhecimento científico. Minc (2005) ressalta sobre a ausência de uma gestão ambiental eficiente nas grandes cidades como São Paulo, e, portanto, conhecer os horizontes do solo, categorias e variações, conforme o Sistema de Classificação de Solos (Embrapa, 2007), permitiria ao educando conhecer o solo para além do conceito de "terra", "chão", mas compreender que o solo é importante recurso natural da geosfera.

Quando perguntado sobre qual a importância dos seres vivos do solo para o plantio (indicador 7) obtivemos respostas em que os alunos não responderam ou não sabiam, em pelo menos metade do grupo; mas respostas genéricas como são essenciais ao solo, importante, ou não, para as plantas sugerem a percepção do aluno sobre a interrelação entre a microfauna no solo e os processos de desenvolvimentos das plantas.

Essa observação, quando analisamos o indica- dor 8 (Os diferentes tipos de solo, fertilidade, importância da adubação, o uso de agrotóxicos na agricultura e suas consequências) é justificado, por algumas respostas como adubar o solo é inserir microrganismos no solo, ou o agrotóxico é como um veneno artificial.

A biodiversidade do solo, de acordo com Silveira e Freitas (2007), é um dos fatores mais importante para a manutenção da fertilidade do solo com a matéria orgânica como folhas, galhos, entre outros, formando a MOS (Matéria Orgânica do Solo) (FAO, 2020). A preservação desta biota pode ser iniciada com ações como não jogar "lixo" no chão, reciclar e reutilizar, valorizar espaços a partir do plantio, entre outras ações ambientais desenvolvidas dentro e fora da escola, simples intervenções que podem corroborar com a biodiversidade do solo (Silveira \& Freitas, 2007).

A partir das respostas da roda de conversa verificou-se que o conhecimento dos alunos se aproxima do solo onde depositamos os resíduos de nosso cotidiano, e não como um recurso natural importante e que deve ser protegido e conservado das ações antrópicas, assim como não percebem o caráter finito do solo, enquanto recurso natural.

Em tal perspectiva, ao analisarmos as habilidades que deveriam ser desenvolvidas em Ciências da Natureza e Geografia em seriação que antecede a atual em curso, percebemos que esses conceitos não foram devidamente desenvolvidos em sala de aula, para que ao aluno essas habilidades estivessem presentes em suas respostas.

A partir da análise da roda de conversa inicial, as demais rodas de conversa e as intervenções foram reprogramas na forma de aulas teóricas e práticas, ainda em ambiente remoto. Com abordagem interdisciplinar e transversal, foram desenvolvidas em temáticas associadas aos indicadores.

As aulas foram realizadas duas vezes por semana, e cada intervenção se referiu a uma aula, com duração de 90 minutos, podendo ser repetidas, ou ampliadas, tendo ocorrido em dois blocos: uso racional do solo e solo e sua relação com o plantio.

Após cada intervenção, o professor realizava uma segunda roda de conversa sobre o tema, com objetivo de avaliar se o conhecimento prévio dos alunos, anteriormente mapeados, foram de alguma forma complementados a partir das intervenções.

Para concluir a fase remota realizaram-se 4 intervenções, que resumiram os conhecimentos sobre o solo e sua relação com o plantio, totalizando 16 intervenções em ambiente remoto.

\begin{tabular}{|c|c|c|c|c|c|}
\hline (C) Terrae Didat. & Campinas, SP & v.17 & $1-12$ & $\mathrm{e} 021042$ & 2021 \\
\hline
\end{tabular}


Assim, as rodas de conversa subsequentes, ainda em ambiente remoto, promoveram um diálogo muito proveitoso entre o professor e os alunos, em que os indicadores propostos foram associados aos objetivos para o desenvolvimento sustentável
(ODS) da Agenda 2030, e a etapa de plantio utilizando os kits preparados pelo professor. A Tabela 1 resume os objetivos de uma das rodas de conversa realizadas e a associação realizada entre os indicadores e os ODS da Agenda 2030:

Tabela 1. Temáticas das rodas de conversa associadas aos objetivos/indicadores definidos e aos DOS da Agenda 2030

\begin{tabular}{|c|c|c|c|}
\hline Tem & Objetivos / Indicadores & ODS Agenda 2030 & Atividades Realizadas \\
\hline $\begin{array}{l}\text { O solo como } \\
\text { recurso na- } \\
\text { tural, valores } \\
\text { e impactos } \\
\text { ambientais } \\
\text { (fevereiro, } \\
2021 \text { ) }\end{array}$ & $\begin{array}{l}\text { Compreender o conceito de solo; } \\
\text { processo de formação; valorizar o } \\
\text { solo como recurso natural esgotável } \\
\text { e finito; justificar a importância do } \\
\text { solo para a humanidade e biodiver- } \\
\text { sidade; introduzir os valores do solo } \\
\text { e seus usos múltiplos; trabalhar os } \\
\text { serviços ecossistêmicos do solo. (1, } \\
2,3,6)\end{array}$ & $\begin{array}{l}\text { 3. Boa saúde e bem-estar } \\
\text { 4. Educação de qualidade } \\
\text { 11. Cidades e comunidades sus- } \\
\text { tentáveis } \\
\text { 13. Combate às alterações cli- } \\
\text { máticas } \\
\text { 15. Vida sobre a Terra }\end{array}$ & $\begin{array}{l}\text { Aula teórica dialogada em } \\
\text { ambiente remoto; } \\
\text { Aula prática com o plantio } \\
\text { de hortaliças, em ambiente } \\
\text { remoto, com o uso dos } \\
\text { kits; } \\
\text { Momento conclusivo } \\
\text { dialogado. }\end{array}$ \\
\hline $\begin{array}{l}\text { Nutrientes } \\
\text { do solo ideal, } \\
\text { fisiologia das } \\
\text { plantas e tipo } \\
\text { de hortaliças } \\
\text { (fevereiro } \\
2021 \text { ) }\end{array}$ & $\begin{array}{l}\text { Introduzir conceitos sobre pedogê- } \\
\text { nese; classificar os tipos de relevos } \\
\text { do Brasil para compreensão da for- } \\
\text { mação dos solos; conhecer o in- } \\
\text { temperismo, tipos de sedimentos e } \\
\text { diferentes tipos de solos; compreen- } \\
\text { der a importância da vegetação para } \\
\text { a preservação dos solos. }(2,4,6)\end{array}$ & $\begin{array}{l}\text { 3. Boa saúde e bem-estar } \\
\text { 4. Educação de qualidade } \\
\text { 12. Consumo e produção sus- } \\
\text { tentáveis } \\
\text { 13. Combate às alterações cli- } \\
\text { máticas } \\
\text { 15. Vida sobre a Terra }\end{array}$ & $\begin{array}{l}\text { Aula teórica dialogada em } \\
\text { ambiente remoto; } \\
\text { Aula prática com o plantio } \\
\text { de hortaliças, em ambiente } \\
\text { remoto, com o uso dos } \\
\text { kits; } \\
\text { Momento conclusivo } \\
\text { dialogado. }\end{array}$ \\
\hline $\begin{array}{l}\text { Biodiversi- } \\
\text { dade do solo, } \\
\text { uso de agro- } \\
\text { tóxicos e a } \\
\text { agroecologia } \\
\text { para preser- } \\
\text { vação do solo } \\
\text { como recurso } \\
\text { natural } \\
\text { (fevereiro } \\
2021 \text { ) }\end{array}$ & $\begin{array}{l}\text { Revisar a intervenções anteriores; } \\
\text { trabalhar a fertilidade e biodiversi- } \\
\text { dade do solo; classificar a fauna do } \\
\text { solo aprofundando o conhecimento } \\
\text { referente a vegetação e sua função } \\
\text { sobre o solo; conhecer os riscos } \\
\text { causados pelo uso do agrotóxico e } \\
\text { da monocultura no meio ambiente; } \\
\text { apresentar a agroecologia como uma } \\
\text { das saídas para a preservação do solo } \\
\text { e demais recursos naturais. }(6,7,8)\end{array}$ & $\begin{array}{l}\text { 2. Fome zero e agricultura sus- } \\
\text { tentável } \\
\text { 3. Saúde e bem-estar } \\
\text { 6. Água potável e saneamento } \\
\text { básico } \\
\text { 4. Educação de qualidade; } \\
\text { 10. Redução da Desigualdades } \\
\text { 11. Cidades e comunidades sus- } \\
\text { tentáveis; } \\
\text { 12. Consumo e produção res- } \\
\text { ponsável; } \\
\text { 13. Ação contra mudança global } \\
\text { do clima } \\
\text { 15- Vida Terrestre. }\end{array}$ & $\begin{array}{l}\text { Aula teórica dialogada em } \\
\text { ambiente remoto; } \\
\text { Aula prática com o plantio } \\
\text { de hortaliças, em ambiente } \\
\text { remoto, com o uso dos } \\
\text { kits; } \\
\text { Momento conclusivo } \\
\text { dialogado. }\end{array}$ \\
\hline $\begin{array}{l}\text { Impactos } \\
\text { Ambientais } \\
\text { e saúde hu- } \\
\text { mana } \\
\text { (fevereiro } \\
2021 \text { ) }\end{array}$ & $\begin{array}{l}\text { Classificar tipos de poluições, tra- } \\
\text { balhar conceito Ambiente e Meio } \\
\text { Ambiente; registro com fotografias } \\
\text { individuais poluição próximo esco- } \\
\text { la, ou residência do aluno, realizar } \\
\text { discussões sobre impactos antró- } \\
\text { picos; compreender impactos am- } \\
\text { bientais como fatores que reduzem } \\
\text { a saúde humana a partir da poluição } \\
\text { dos recursos naturais. }(2,5)\end{array}$ & $\begin{array}{l}\text { 6. Água potável e saneamento } \\
\text { básico } \\
\text { 13. Ação contra mudança global } \\
\text { do clima } \\
\text { 17. Parcerias e meio de imple- } \\
\text { mentação }\end{array}$ & $\begin{array}{l}\text { Aula prática como registro } \\
\text { individual de fotos sobre } \\
\text { poluição para produção de } \\
\text { narrativas; } \\
\text { Momento conclusivo dia- } \\
\text { logado sobre os registros } \\
\text { produzidos. }\end{array}$ \\
\hline $\begin{array}{l}\text { Hortaliças: } \\
\text { tipos e cui- } \\
\text { dados } \\
(\text { março de } \\
2021)\end{array}$ & $\begin{array}{l}\text { Introduzir conceito de reprodução } \\
\text { das plantas, grupos das angiosper- } \\
\text { mas; compreender função das flores } \\
\text { e frutos; conhecer principais tipos } \\
\text { de hortaliças; destacar os principais } \\
\text { cuidados com as culturas plantadas; } \\
\text { desenvolver parcerias, com profes- } \\
\text { sores da escola, para trabalhar o solo } \\
\text { de forma interdisciplinar e transver- } \\
\text { sal. }(6,7)\end{array}$ & $\begin{array}{l}\text { 2. Fome zero e agricultura sus- } \\
\text { tentável. } \\
\text { 3. Saúde e bem-estar } \\
\text { 4. Educação de qualidade } \\
\text { 10. Redução das Desigualdades } \\
\text { 12. Consumo e Produção Res- } \\
\text { ponsáveis } \\
\text { 15. Vida Terrestre }\end{array}$ & $\begin{array}{l}\text { Aula teórica dialogada em } \\
\text { ambiente remoto; } \\
\text { Aula prática com o plantio } \\
\text { de hortaliças, em ambiente } \\
\text { remoto, com o uso dos } \\
\text { kits; } \\
\text { Momento conclusivo } \\
\text { dialogado. }\end{array}$ \\
\hline (C) Terrae Didat & ae Didat. & $1-12$ & $\mathrm{e} 021042$ \\
\hline
\end{tabular}


Relembrar o momento do Plantio Monitorado e o envolvimento dos alunos; destacar a importância do uso dos kits no plantio para a reali-

Revisando conceitos e o plantio monitorado zação das aulas práticas; reconhecer o solo para além do conceito de chão; reforçar a importância da agroecologia para o plantio orgânico.

(março de 2021)

Revisão dos indicadores no Plantio Monitorado

Defensivos ecológicos: controle biológico a partir do uso de defensivos na agroecologia,

(março de 2021)

Durante as atividades práticas houve a inclusão dos professores da escola nos momentos de discussão sobre os objetos de aprendizagem solo/plantio, com foco nos ODS da Agenda 2030, discutimos o Bem-estar e saúde emocional, o respeito à resiliência do solo, Vida sobre o Solo interferindo nos demais recursos naturais a partir do Consumo e Produção Responsável (Fig. 1).

As aulas práticas também foram registradas por meio do ambiente virtual de aula, com o uso do kit

A transição do ensino remoto para o presencial envolveu o ensino híbrido, em que intervenções na forma de roda de conversa foram realizadas virtualmente, e na escola aplicamos a construção da horta e pomar. Nesta etapa, também foram realizados o mapeamento do terreno e aulas nos laboratórios para medir o pH do solo, avaliar a compactação e planejar o manejo do solo.

\section{Considerações Finais}

No cenário do isolamento social promovido pela pandemia de Covid-19 as diferenças entre a *educação em escolas públicas e escolas privadas foram amplificadas, e mostraram as dificuldades dos professores das escolas públicas em manter o interesse dos alunos na educação a distância (Gabriel et al. 2020), e evidenciou um fato contundente: a escola pública no Brasil, onde a grande maioria das crianças tem acesso à educação básica, ainda está longe do mínimo ideal.
2- Fome zero e agricultura sustentável

3- Saúde e bem-estar

4- Educação de qualidade

10- Redução das desigualdades

11- Cidades e comunidades sustentáveis

12- Consumo e produção sustentável

15- Vida terrestre

17- Parcerias e meio de implementação

4. Educação de qualidade

11. Cidades e comunidades sustentáveis

12. Consumo e produção responsável

15. Vida Terrestre

Aula teórica dialogada em ambiente remoto;

Aula prática com o plantio de hortaliças, em ambiente remoto, com o uso dos kits;

Momento conclusivo dialogado.

Aula teórica dialogada em ambiente remoto,

Aula prática com o plantio de hortaliças, em ambiente remoto, com o uso dos kits;

Momento conclusivo dialogado.
Apesar do grande número de canais de comunicação, durante a pandemia, os professores experimentaram a solidão profissional e o isolamento educacional. Durante a transição para o ensino remoto, a comunicação presencial se perdeu não apenas entre o professor e os alunos na sala de aula, mas também entre os próprios professores. As discussões sobre o ensino, as trocas de opiniões sobre suas práticas, para muitos professores também foram interrompidas. (Ortega \& Rocha, 2020, p. 312)

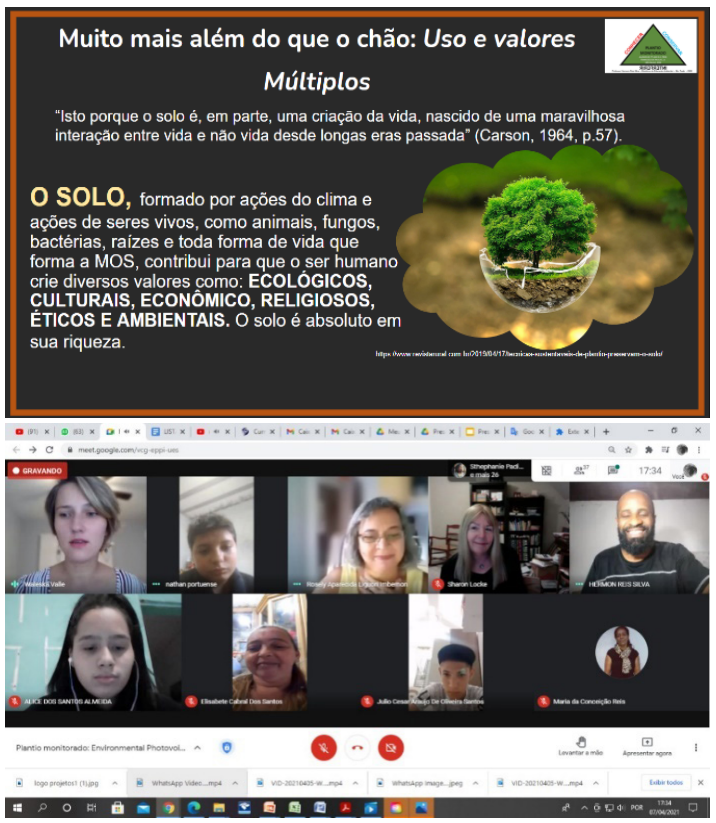

Figura 1. Aula remota em ambiente virtual Google. Meet com alunos, professores, pais e convidados

\begin{tabular}{c|c|c|c|c|c}
\hline (C) Terrae Didat. & Campinas, SP & v.17 & $1-12$ & $\mathrm{e} 021042$ & 2021 \\
\hline
\end{tabular}




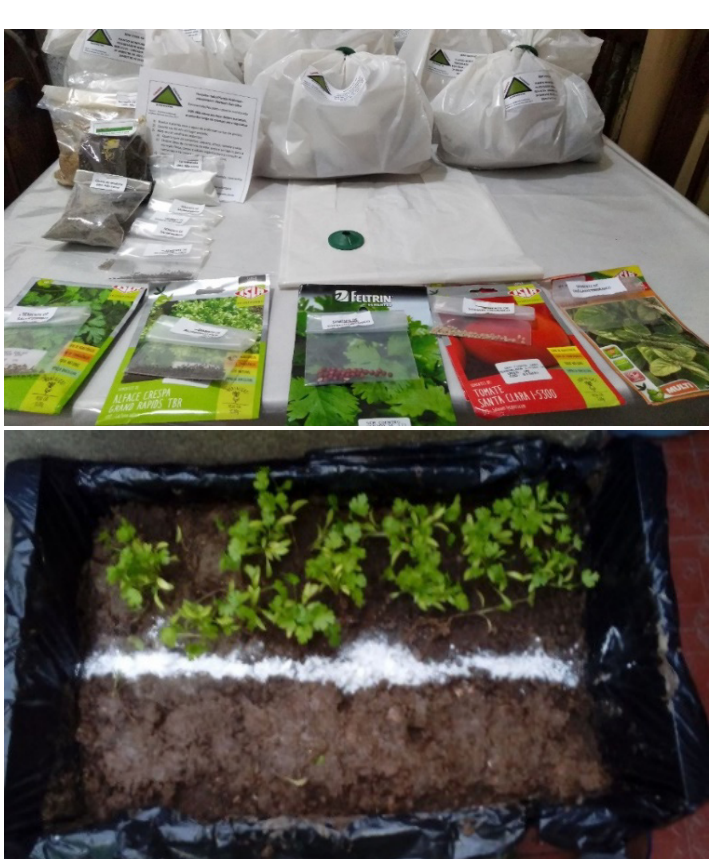

Figura 2. Kit plantio entregue aos alunos para aula prática em ambiente remoto

Deve haver reflexão sobre um ponto: quais são as influências psicológicas da pandemia em alunos e professores nas salas de aula da educação básica? Algumas questões podem ser formuladas, e deveríamos pesquisar, junto a profissionais de saúde e/ ou conselheiros escolares, buscando compreender as maneiras como os alunos descrevem o efeito da pandemia em sua autoeficácia educacional e moral (Haleen et al., 2020), além de explorar, em grande escala, a influência psicológica sobre professores e corpo discente. $\mathrm{O}$ resultado das pesquisas seria valioso para as instituições educacionais (Robinson-Neal, 2021, p. 3).

Ao estabelecermos a contextualização dos ensinos fragmentados em disciplinas, como sugere Morin (2000), resolvemos um campo de discussões voltado para a complexidade e amadurecimento de novos desafios. A partir de tal constatação, esta pesquisa apresentou inovações importantes no campo do ensino de geociências, ao propor intervenções interdisciplinares e transversais, tendo o projeto da horta escolar como tema gerador.

From developing competences in primary pupils to engage higher education students, sustainability projects also demonstrate that integral approaches are urgently needed. (Wamsler, 2020 apud Vasconcelos \& Orion, 2021)

Jensen et al (2019) apontam que ao curso desta última década, a adoção de projetos com foco para a educação para a sustentabilidade, com a inclusão de componentes sociais e princípios verdes, promoveram diversas iniciativas que alteraram os curriculos escolares. No Brasil, a inserção dos temas relacionados ao meio ambiente, indicados pelos temas transversais, não efetivou a inserção da temática ambiental em nossos sistemas educacionais, o que Vasconcelos \& Orion (2021) apontam ser um paradigma da educação para a sustentabilidade que criou uma enorme lacuna entre as intenções da Agenda 2030 e o cumprimento de seus objetivos. [...] Essa lacuna constitui parte da essência de um problema educacional mundial.

A temática solo, no contexto da educação ambiental, não apresenta um enfoque aprofundado na educação formal, quando comparamos com temas como resíduos sólidos (lixo, reciclagem etc.) e água, recorrentemente enfocados em projetos escolares.

[...] co conteúdo relacionado aos solos tem sido abordado, em muitos casos, de forma descontextualizada, o que deixa lacunas no que tange à necessidade de se estudar a temática como algo relevante para o entendimento do papel dos solos para a biosfera e, principalmente, para a sociedade. (Souza et al., 2021 p.11).

Considerando a forma como se apresenta o conteúdo sobre os solos do Brasil em muitos dos livros didáticos, é possível observar claramente a necessidade de contextualização do assunto com espaço de vivência dos discentes

A pandemia promoveu alterações no cenário social, principalmente no que se refere à manutenção de uma educação de qualidade. Assim, ao associamos o ensino formal e não formal, envolvendo também a comunidade escolar em momento de isolamento social em novas perspectivas de aprendizagem, tendo como temática o solo e o plantio no ambiente remoto, ou seja, na casa do aluno, nos permitiu um aporte, também, da agricultura familiar. Ao buscarmos interrelacionar o ensino remoto e o ensino híbrido, identificamos abordagens metodológicas que nos possibilitaram o desenvolvimento da pesquisa, sem perdas para os alunos participantes, pois o "ensino híbrido vai além da complementaridade entre o presencial e o virtual ao instituir um espaço intersticial produtor de identidades e de culturas" (Bhabha, 2002) e está fundado pelo "diálogo, compondo uma força transgressora do discurso e da prática educacional centrado na transmissão de informações" (Almeida et al., 2020).

A adoção do ensino híbrido na fase final do projeto, com o retorno à escola para construção 


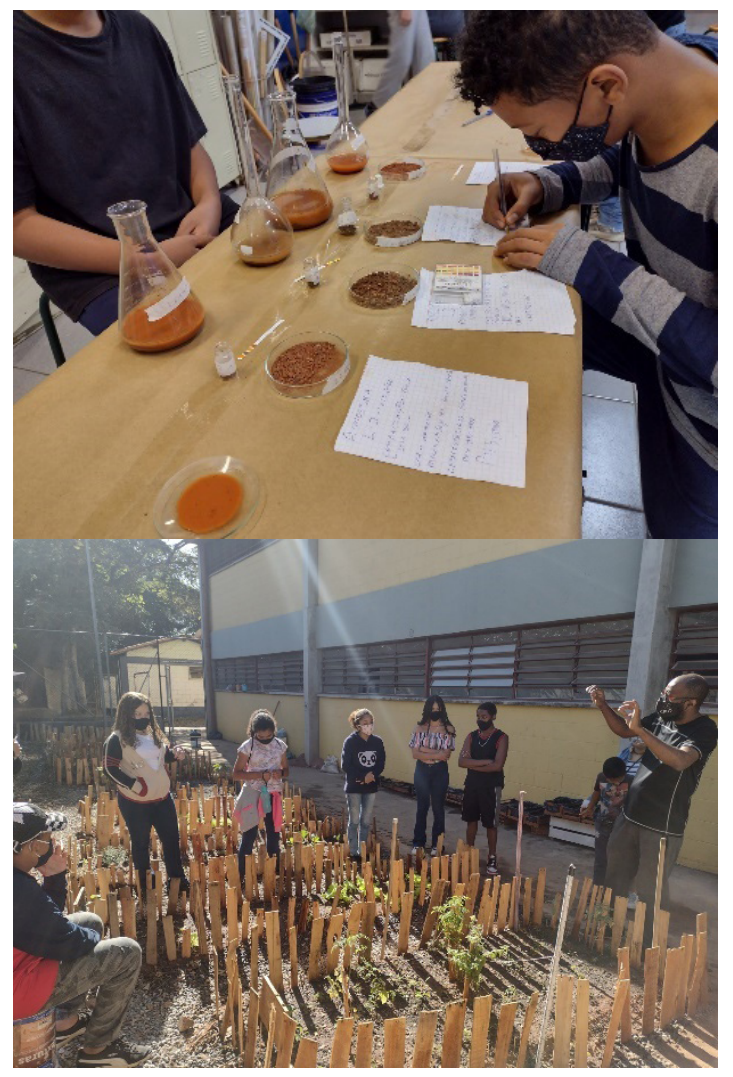

Fig. 3 Intervenções na etapa de ensino híbrido, com a construção da horta e plantio

da horta, impulsionou as conexões entre o conhecimento geocientífico enfocado nas intervenções em aulas remotas, e o conhecimento advindo da experiência a partir das atividades práticas realizadas nas residências dos alunos com seus familiares, promovendo a articulação entre teoria e prática, ressignificação da prática e reconstrução da teoria (Almeida, 2004 apud Almeida et al. 2020 p. 89).

Ao aplicarmos o ensino híbrido no contexto de metodologias ativas (a partir das intervenções/aulas práticas) e da pesquisa-ação, nos baseamos no pressuposto de que essas alternativas pedagógicas possibilitariam colocar em foco os conteúdos definidos no processo de ensino e aprendizagem do aluno, de forma que ele se envolveu na aprendizagem por meio da investigação e/ou da resolução de problemas (Valente, 2018, p. 27), e a pesquisa-ação foi a estratégia pela qual o professor atingiu os objetivos para o desenvolvimento das habilidade previstas.

Salientamos que somente após a transição do ensino remoto para o ensino presencial, inicialmente no formato híbrido, a horta foi definitivamente construída na escola, o que demonstra que o ensino remoto, associado ao ensino híbrido, permite desenvolver atividades práticas, como a que envolveu o solo e plantio, de forma que o retorno ao ensino presencial se tornou somente mais uma etapa do projeto, sem pressões psicológicas.

Os efeitos da pandemia expuseram problemas na educação do país que afetam os programas de formação continuada para professores, tanto nos níveis administrativos quanto curriculares. Para além de tais aspectos, devemos considerar os contextos de aprendizagem em que o ensino se deu durante o período de isolamento social, o uso de tecnologias pouco ou nunca aplicadas, principalmente em escolas públicas, e o papel dos pais e/ou familiares (Cristol et al., 2021).

No contexto do retorno às aulas presenciais, seja no formato híbrido ou não, Darling-Hammond \& Hyler (2020) apontam a necessidade de os formuladores de políticas públicas e gestores educacionais em estabelecer apoio colaborativo para todos os níveis de educadores, de forma a atender às necessidades sociais, emocionais e acadêmicas dos alunos pós-pandemia.

Em tal perspectiva, tais procedimentos se configuram como de vital importância, principalmente dos professores do ensino fundamental séries iniciais $\left(1^{\circ}\right.$ ao $\left.5^{\circ}\right)$, na medida em que muitos desses professores tiveram que aprender a "ensinar" em ambientes educacionais que jamais utilizaram anteriormente, durante e pós-Covid, e o projeto da horta escolar permitiu aos alunos participantes superarem esse momento.

\section{Referências}

Almeida, F. J., Almeida, M. E. B., \& Silva, M. G. M. (2020). In: Almeida, F. J. de, Almeida, M. E. B. de, \& Silva, M. G. M. da (orgs). (2020). De Wuhan a Perdizes. Trajetos educativos. São Paulo: EDUC. e-book. ISBN 978-65-87387-15-4. URL: https://www.pucsp.br/educ/downloads/trajetos_ educativos.pdf. Acesso 07.09.2021.

Almeida, M. E. B. (2004). Inclusão digital do professor: formaçãa e prática pedagógica. São Paulo: Articulação Universidade Escola.

Bacich. L., Neto, A. T., \& Trevisani, F. M. D. (2019). Ensino Híbrido: personalização e tecnologia na educação. Porto Alegre, Penso.

Barbosa, M. C. S., \& Horn, M. G. S. (2008) Projetos pedagógicos na Educação Infantil. Porto Alegre: Artmed, 2008.

Bhabha, H. (2002). O local da cultura. Belo Horizonte: Ed. UFMG.

Brasil. Ministério da Educação. (2018). Base Nacional Comum Curricular: versão final. Brasília. URL: http://basenacionalcomum.mec.gov.br/images/BNCC_EI_EF_110518 versaofinal_site.pdf. Acesso 15.04.2021.

Carson, R. (1964). Primavera silenciosa. São Paulo: Melhoramentos.

Cristol, D., Gimbert, B. (2021). Preservice teachers selfawareness needs post-pandemic. Academia Letters, Article 256, 1-10. doi: 10.20935/AL256.

Darling-Hammond, L., \& Hyler, M. E. (2020). Preparing 
educators for the time of COVID... and beyond. European Journal of Teacher Education, 43(4), 457-465. doi: 10.1080/02619768.2020.1816961

Food and Agriculture Organization (FAO), Intergovernmental Technical Panel on Soils (ITPS), Global Soil Biodiversity Initiative (GSBI), U.S. National Cooperative Soil Survey Characterization Database (NCSS-SCDB), European Commission (EC). (2020) State of knowledge of soil biodiversity: Status, challenges and potentialities, Summary for policy makers. Roma, FAO. URL: https://doi.org/10.4060/ cb1929en.

Food and Agriculture Organization, FAO (2021). Food and Agriculture Organization of the United Nations. ONU.

Food and Agriculture Organization, FAO (2015). Food and Agriculture Organization of the United Nations. Soil is a nonrenewable resource. Its preservation is essential for food security and our sustainable future. Italy. ONU.

Freire, P. (1996). Pedagogia da Autonomia: Saberes necessários à prática educativa. São Paulo: Paz e Terra.

Freire, P. (1983). Pedagogia do oprimido. São Paulo: Paz e Terra. Gabriel, N. S., Marçal, G. A., Imbernon, R. A. L., \& Pioker-Hara, F. C. (2021) O retorno às aulas no pós-pandemia: estudo de caso e análise comparativa entre o ensino público e o ensino privado. Terre Didatica, 17(Publ. Contínua), 1-13, e021005. doi: 10.20396/td.v17i0.8663375.

Giroux, H. A. (1997). Os professores como intelectuais: rumo a uma pedagogia crítica da aprendizagem. Trad. Daniel Bueno. Porto Alegre: Artes Médicas. 528p. ISBN 85-7307-301-2.

Guarda, G. N., Luz, T. N., Rodrigues, T., \& Beltrame, L. M. (2017). A roda de conversa como metodologia educativa: o diálogo e o brincar oportunizando o protagonismo infantil na sala de aula. In: Educere, Formação de professores: contexto, sentidos e prática. IV Sem. Int. de Representações Sociais, Subjetividade e Educação-SIRSSE; VI Sem. Intern. Profissionalização Docente (SIPD/Cátedra UNESCO). URL: https://educere.bruc.com.br/arquivo/ pdf2017/26991_13947.pdf. Acesso 30.08.2021.

Haleem, A., Javaid, M., Vaishya, R., Deshmukh, S. G. (2020). Areas of academic research with the impact of COVID-19. The American Journal of Emergency Medicine, 38(7): 1524-1526. doi: 10.1016/j.ajem.2020.04.022.

Harrison, R., Strahm, B., \& Yi, X. (2010). Soil education and public awareness. In: Verheye, W. H. ed., (2010). Plant Growth and Crop Production, v. 3, Cap. 33, e-ISBN: 978-184826-369-7. ISBN: 978-1-84826-819-7, 492p.

Jensen, C. D., Kotaish, M., Chopra, A., Jacob, K. A., Widekar, T. I., \& Alam, R. (2019). Piloting a Methodology for Sustainability Education: Project Examples and Exploratory Action Research Highlights. Emerg. Sci. J. 3, 312-326.

Lins, M. R. C., Araújo, M. R., \& Minervino, C. A. S. M. (2013). Estratégias de aprendizagem: um estudo teórico. In: Minervino, C. A. S. M., \& Nóbrega, J. N. (Orgs.). (2013) Aprendizagem e emoção: estudos na infância e adolescência. Casa do Psicólogo. p. 60-91.

Morin, E. (2003) Uma ciência com consciência. Rio de Janeiro: Bertrand Brasil, 350 p. ISBN 8528605795.

Morin, E. (2000) Os sete saberes necessários à educação do futuro. Trad. Catarina Eleonora F. da Silva e Jeanne Sawaya Carvalho. 2 ed. São Paulo. Cortez. Brasília, DF: UNESCO.

Organização das Nações Unidas, ONU. (2015). Agenda 2030. ONU. URL: http://www.agenda2030.org.br/sobre/.
Acesso 20.02.2017.

Ortega, L. M. R., \& Rocha, V. F. (2020). O Dia Depois de Amanhã. Na realidade e nas Mentes. O que esperar e a Escola Pós-Pandemia? Pedagogia em Ação, 13(1), 302-314. URL: http://200.229.32.43/index.php/pedagogiacao/article/view/23782. Acesso 20.03.2021.

Robinson-Neal, A. (2021). Reflections on Educational Practice: Covid-19 Influences. Academia Letters, Article 176, 1-6. 10.20935/AL176.

Roldão, M. C. (2010). Ensinar e aprender: o saber e o agir distintivos do profissional docente. In: Ens, R. T., \& Behrens, M. A. orgs. (2010). Formação do professor: profissionalidade, pesquisa e cultura escolar. Curitiba: Champagnat. p. 25-42.

Santamaria Filho, A. R., Nogueira, J. M., Cabral, P. G. F., Ramos, E. N., \& Sandri, E. B. (2015). Eixo 3. Sustentabilidade da Produção Agropecuária, Segurança Alimentar e Serviços Ambientais. In: Relatório, Conferência Governança do Solo, 25 a 27 de março de 2015, Brasília, DF. Tribunal de Contas da União. $56 p$.

Schroeder, D. (2017). Solos. Fatos e Conceitos. Trad. Lopes, A. S. São Paulo, ANDA. 2017. Sistema Brasileiro de Classificação de Solo. 5 ed. Brasília. DF: Embrapa.

Silveira, A. P. D., \& Freitas, S. S. (2007). Microbiota do Solo e Qualidade Ambiental. Campinas: Instituto Agronômico. 312p. ISBN: 978-85-85564-14-8

Souza, A. S., Furrier, M., \& Lavor, L. F. de. (2021). Solos nos livros didáticos: contextualização e proposta de mapas didáticos. Terre Didatica, 17(Publ. Cont.), 1-13, e021010. doi: $10.20396 /$ td.v17i0.8663686.

Thiollent, M. (2005) Metodologia da Pesquisa-ação. 14 ed. São Paulo: Cortez.

Thiollent, M. (2011) Metodologia da Pesquisa-ação. 18 ed. São Paulo: Cortez.

Valente, J. A. (2014) Blended learning e as mudanças no ensino superior: a proposta da sala de aula invertida. Educar em Revista, (spe 4). Dossiê Educação a Distância. doi: 10.1590/0104-4060.38645.

Vasconcelos, C., Orion, N. (2021) Earth Science Education as a Key Component of Education for Sustainability. Sustainability, 13, 1316. doi: 10.3390/su13031316.

Vicente, M. C., Bertholoto, D. M. (2020) O ensino de solos nos anos iniciais do Ensino Fundamental: uma abordagem baseada em livros didáticos de Ciências após aprovação da Base Nacional Comum Curricular. Revista Educação Pública, 20(39). doi: 10.18264/REP.

Wamsler, C. (2020). Education for sustainability: Fostering a more conscious society and transformation towards sustainability. Int. J. Sustain. High. Educ., 21, 112-130. doi: 10.1108/IJSHE-04-2019-0152.

Yin, R. K. (2001). Estudos de casos Planejamentos e Métodos. Trad. Grassi, D. Porto Alegre: Bookman.

Yin, R. K. (2016). Pesquisa qualitativa do início ao fim. Trad. Bueno, D. Penso. Porto Alegre, 2016.

Zanella, A. G. (2019). Avaliação de bioporos na vitrine tecnológica de agroecologia do município de Cascavel, PR. Universidade Federal de Fronteira do Sul, Curso de Agronomia, Trabalho de Conclusão de Curso, TCC. 33p. URL: https:// rd.uffs.edu.br/bitstream/prefix/3740/1/ZANELLA.pdf. Acesso 25.01.2021.

Zuñiga, R. (1981). La recherche-action et le controle du savoir. Revue Internationale d'Action Communautaire, 45(5), 35-44. 